\title{
Managing Water Resources for Environmentally Sustainable Irrigated Agriculture in Pakistan
}

\author{
MUHAMMAD AFZAL
}

\begin{abstract}
Pakistan's agriculture is almost wholly dependent on irrigation and irrigated land supplies more than 90 percent of agricultural production. Irrigation is central to Pakistan's economy. Massive investments in irrigation contributed to the development of one of the largest Indus Basin Irrigation System. Despite heavy budgetary inputs in irrigation system, it is facing shortage of resources and suffering from operational problems. The sustainability of irrigated agriculture is threatened due to problems of waterlogging and salinity, inadequate operation and maintenance, insufficient recovery of O\&M expenditure, inequitable distribution, environmental degradation, institutional issues etc.

The growing scarcity of water sets the future stage for intensive competition over water between agriculture and non-agricultural users. The growing need for food and fibre requirements of increasing population further limits the per capita availability of water. Due to the limited prospects for expanding irrigation facilities, the projected increase in irrigated agriculture will have to come from significant improvement in the performance of existing systems. Policy-makers and planners are of the view that Pakistan's irrigated agriculture requires new strategies to enhance input efficiency and maintain and improve the quality of the resource base and to get the irrigation system out of crises.

There is a global movement for searching a new type of relationship between the managers of irrigated agriculture and farmers. Such options are being considered by government at various levels to put the system on sustainable development path. In addressing the environmentally sustainable water resource management in Pakistan, the paper makes an attempt to provide an over-view of water resource issues and options.
\end{abstract}

\section{INTRODUCTION}

Irrigation in Pakistan is at a critical juncture, where increases in irrigated area are exceeding sustainable limits and adverse environmental effects of waterlogging, salinity and mining of groundwater are threatening the resource base of irrigated agriculture. This situation requires new solutions to maintain the resource base, improve agriculture productivity and sustain irrigated agriculture in Pakistan.

The growing scarcity of water sets the future stage for intensive competition over water between agricultural and non-agricultural users. Due to the limited prospects for expanding irrigation facilities, the projected increase for irrigated agriculture will have to come from significant improvement in the performance of existing systems.

Muhammad Afzal is Chief Economist at Planning Division (Water), Water and Power Development Authority, Lahore.

Author's Note: The views and interpretations in this paper are those of the author and should not be attributed to WAPDA. 
Pakistan's agriculture is almost wholly dependent on irrigation-irrigated land supplies more than 90 percent of agricultural production, with gross commanded area of 16 million hectares. The water sector investment planning study has estimated food, fibre and edible oil shortfall of $23.5 \mathrm{~m}$. tons in the year 2000 and $48.5 \mathrm{~m}$. tons in the year 2013. The annual agricultural growth rate of 6 percent has been estimated to reverse the trend of deficits in food, fibre and edible oils.

To achieve the desired target it is imperative to enhance crop production and productivity through a considerable change in production system by putting irrigation system on sustainable development path.

In addressing the environmentally sustainable water resources management in Pakistan, this paper makes an attempt to provide an overview of water resources issues and options in Pakistan.

The paper is divided into three sections. Section I describes Pakistan's water scene including quantum, potential and allocation. Major sustainability issues have been discussed in Section II. Section III discusses the future challenges and options that Pakistan Water Sector may opt.

\section{WATER SCENE IN PAKISTAN}

\section{Present Status of Irrigation System}

\section{Surface Water Development}

The Indus Basin Irrigation System (IBIS) is the world's largest contiguous irrigation system. Since 1947, Pakistan implemented the Indus Basin Replacement Works Project (IBRWP) with the Bank as the lead donor. Under the IBRWP 39.54 million acres were brought under irrigation to create the world's largest contiguous and unified irrigation system. It consists of the Indus River and its major tributaries, 3 major reservoirs (Tarbela, Mangla, and Chashma), 19 barrages, 12 link canals, 43 canal commands, and over 107,000 watercourses. The length of canals total $61,000 \mathrm{kms}$, and in addition watercourses, farm channels, and field ditches cover another 1.6 million kms. Typical watercourse commands range from 200 to 700 acres. The flows to the Indus are from glacier and snow melt, as well as from rainfall outside the Indus Plain [World Bank (1995)].

During the decade ending 1959-60, the canal head withdrawals had increased to an average of 78.6 MAF against 64 MAF at the time of independence. This increase is attributable to the storage reservoirs of Mangla, Chashma and Tarbela which became operational in 1967, 1971 and 1976 respectively. The storage releases of Mangla and Chashma average 5 MAF and with the addition of Tarbela, it has gone upto 15 MAF during the last ten years. While bulk of the storage supplies are utilised during the Rabi, they have also been available in the critically water scarcity periods of early and late 
Kharif for the sowing and maturing of kharif crops. Although the past surface water development has materially increased the extent of irrigated lands, the greater control on the water supplies coupled with enhanced water diversions have contributed to increased agriculture production [Mulk and Mohtadullah (1991)].

About 2.2 million ha of irrigated land is outside Indus Canal Commanded Area (CCA), scattered in relatively small parcels with water coming from open wells, tubewells, life pumps, karezes, springs, and small diversions. Generally, water supply in these system is uncertain and varies with season and location.

\section{Groundwater Development}

Most of the Indus Basin has been formed as a result of alluvium deposits derived by rivers from the mountain ranges in the north. There is a vast unconfined aquifer of around 6 million ha covering most of this area. The hydrogeological conditions are mostly favourable for pumping by tubewells. Groundwater quality is variable with about 79 percent of area in Punjab and 28 percent of area in Sindh as fresh groundwater suitable for irrigation.

By the 1950's large area in the Indus basin became waterlogged and soil salinity increased, adversely affecting the agricultural productivity. Government involvement in the groundwater development began with efforts to control the "twin menaces" of waterlogging and salinity by providing drainage. The Government embarked on a series of SCARPs in the late 1950s aimed at lowering the groundwater table by providing "vertical drainage" through large capacity, deep tubewells (60-140 litres per second capacities and depth of 40-120 meters). Because of better economic returns, priority was given to locating SCARPs in the area with groundwater quality suitable for supplemental irrigation, making the drainage a by-product in effect. Over the last three decades about 13,500 STWs have been installed by the Government in 36 projects covering a gross area of about 3.7 mha. Most of the STWs were equipped with electrically powered motors and deep turbine pumps with a relatively large capacity about 3 cusecs $(.085$ cubic meters/second). Almost 75 percent of all STWs were installed in the Punjab8,000 in fresh groundwater areas and 1,800 in saline groundwater areas. In saline groundwater areas the STWs pumped water into drains or, when this was not possible, into the larger canals. In the fresh groundwater areas, water from STWs was normally pumped into watercourses and used for irrigation alongwith surface water supplies.

The introduction of tubewell technology by the public sector was followed by a virtual explosion in the private tubewells development. Currently there are over 300,000 PTWs installed for irrigation purposes, of which 80 percent are in the Punjab, and they supply 40 percent of total irrigation water. PTWs are predominantly small shallow wells, which use locally manufactured engines and centrifugal pumps. The average capacity of these wells is one cusec $\left(0.028 \mathrm{~m}^{3}\right.$ per second $)$ and upto a maximum of two cusecs. 
More importantly, as yields and input levels rose, so did the importance of timely and adequate water supplies. By installing PTWs, farmers reduce their risks of crop failure and improve yields by smoothing out natural and operational fluctuations in water supplies from the canal system. Even in the STWs areas of Punjab there are more than 50,000 PTWs. While returns to tubewells are high, the utilisation rates are very low. PTWs are used by both headenders and tailenders but the level of reliance on groundwater is higher in the latter case. Most PTWs are owned by medium to large farmers who have holdings of over five ha. Presently, there is neither any mechanism for allocating groundwater rights nor for regulating its use. An owner of land can install a tubewell and begin pumping groundwater. In some areas there has been overexploitation due to anarchic private tubewell development [World Bank (1995a)].

\section{Development Potential}

The committee on water resources and management in its report (1987) submitted to National Commission on Agriculture had estimated the future water potentials as shown in Table 1. The data show the possible magnitude for development of water from various physical sources. The scope for conservation of water from lining of distributaries and minor canals was recognised to be 4 MAF. There could be deviation in the data on water potentials as a result of further research.

Table 1

Potential for Water Development

\begin{tabular}{clccc}
\hline & & \multicolumn{3}{c}{ Quantity (MAF/Year) } \\
\cline { 3 - 5 } Sr. & \multicolumn{3}{c}{$\begin{array}{c}\text { At Water- } \\
\text { Course Head }\end{array}$} & $\begin{array}{c}\text { At } \\
\text { Formgate }\end{array}$ \\
\hline No. & \multicolumn{1}{c}{ Mode } & At Source & 15.00 & 12.00 \\
1. & Surface Water* & 20.00 & & \\
2. & Groundwater Development & & - & 4.75 \\
& $\quad$ (i) Conventional & 5.00 & - & 4.75 \\
& $\quad$ (ii) By Skimming & 5.00 & 15.00 & 12.00 \\
3. & Watercourse Improvement & & 5.00 & 4.00 \\
4. & Minor Canal Lining & & & 8.00 \\
5. & Riverain Storage** & 12.00 & 35.00 & 37.50 \\
& Total & 42.00 & & \\
\hline
\end{tabular}

* Flow diversion and storage. **Alternate for surface water storage.

The development of water potential shown in the Table involves different types of works and investment implications. The surface water potentials can be exploited only with the construction of storage dams, remodelling of existing system and construction of new canals. Storage facilities require huge investment and longer construction period and political consensus. The storage dam even if started today will not be ready by the 
year 2000 to deliver water to the system. The possible alternative till surface storage facilities are constructed are groundwater, watercourse improvement, canal lining and riverain area development.

The potential for the development of groundwater by conventional means can be exploited quite readily by increasing the utilisation of existing tubewells and by installation of new tubewells. The potential for skimming of groundwater although quite substantial will be developed rather slowly since the technology for it has yet to be developed. The studies by Water Course and Monitoring Directorate have shown that the improvement of watercourses as a mean of water conservation can produce quick results in respect of agricultural productivity. Monitoring studies have shown Benefit Cost Ratio of this programme in the range of 2:1. The activity is divisible as the size of programme can be governed depending on the resources which can be allocated. In watercourse improvement and tubewell development farmers share major portion of capital costs.

According to prevailing technology in Pakistan, canal lining particularly of the existing system has to proceed at a slow pace as in the flowing system the work on canal lining can proceed during canal closures. In case the canals are closed for full season the farmers have to be compensated for crop losses. This will be an additional item in cost composition of canal lining.

Operational management of the system has potential of water saving and reallocation within the system. A study by World Bank has shown that the surpluses which can be reallocated are 1.945 MAF in Punjab and 5.814 MAF in Sindh. Trading/Bartering of surplus water within provinces or between provinces through operational management can increase the national agricultural productivity. Research by some workers has shown substitution between water and fertilisers. This research has shown to attain optimally of water use by using less water by increasing the doses of fertiliser. WAPDA at Mona Reclamation and Experimental Project has shown raising of crops with less number of irrigations in high watertable areas. The results of such research may be consolidated and policies framed to save/optimise water use within feasible economic framework. We feel, there is large scope for saving water by integrated management of the system and substitution among water and non-water inputs by adopting optimal pricing policies; besides conservation of water by canal lining [Shafiq and Naqvi (1993)].

\section{Water Sector Investment Allocations}

Water sector allocations are made to develop the irrigation infrastructure to maintain and augment the irrigation water supplies. The past development plans in the water sector have been reflected in the successive five year plans. A review of these

plans brings out that the public sector allocation for water sector have continued to decline. Water Sector plan allocation at current prices are depicted in Table 2. 
Table 2

Water Sector Allocations (Current Prices)

\begin{tabular}{lcc}
\hline Plan Period & $\begin{array}{c}\text { Allocation } \\
\text { (Million Rs) }\end{array}$ & $\begin{array}{c}\text { Percentage of } \\
\text { Total Plan_ }\end{array}$ \\
\hline First (1955-60) & 1311.9 & 24 \\
Second (1960-65) & 865.9 & 15 \\
Third (1965-70) & 2180.9 & 17 \\
Fourth (1970-75) & 2500.0 & 15 \\
Fifth (1978-83) & 17120.0 & 10 \\
Sixth (1983-88) & 32000.0 & 10 \\
Seventh (1988-93) & 28430.0 & 8 \\
Eighth (1993-98) & 55570.0 & 7 \\
\hline
\end{tabular}

The expenditure on the Indus Basin Project (IBP) (Rs 12.4 billion) were kept outside the plans and it was from the Fifth Plan that these were brought within the plans. Although allocations for the Water Sector were substantially increased in Fifth and Sixth Plans, their share in the total development plan came down to 10 percent from the earlier levels of 15 to 17 percent. In the Seventh Plan it further fell to 8 percent, and in Eighth Plan, it came down to 7 percent [Government of Pakistan (Various Issues)].

\section{MAJOR SUSTAINABILITY ISSUES}

The various approaches started in succession did not encompass the irrigated agriculture related problems in totality and problems continued to accumulate, resulting in inefficient and unsustainable irrigation system leading to stagnant agricultural production. The issues identified in Revised Action Programme and subsequently highlighted in Water Sector Investment Planning Study are vis-à-vis. Water logging and salinity, inequitable water distribution and low delivery efficiency, water scarcity, low O\&M cost recovery, advanced irrigation technologies, SCARP transition, environmental protection, data management, project preparation and implementation, monitoring and evaluation, low water delivery efficiencies, beneficiary participation, lack of coordination between agriculture and irrigation departments etc. Major issues related to irrigation management are described in brief as under:

\section{Waterlogging and Salinity}

Due to flat topography, poor natural drainage, porous soil and semi-arid climate characteristics of the Indus Basin, extensive irrigation system without adequate drainage has led to rising water tables and eventually salinity. Presently about 30 percent of the irrigated area is waterlogged, 13 percent highly waterlogged, while soil salinity is 
estimated to rob farmers of 25 percent of potential production of major crops [World Bank (1994)].

\section{Secondary Salinity}

Though, with the inception of Salinity Control and Reclamation Projects (SCARPs), waterlogging has greatly been reduced, the incidence of salinity is still on the increase. This is a specific phenomenon of secondary salinisation which does not seem to have been reversed so far. Salt balance for whole of Pakistan has been reported as negative because more salt is entering in the system than leaving. Sustainability of irrigated agriculture in the long run would be threatened by accumulation of salts into the soil and concentration of salts in Fresh Ground Water (FGW) zone now being used to supplement irrigation water. Except for projects around Left Bank Outfall Drain (LBOD), drainage effluent is being recycled within the system in one form or the other.

Over mining of groundwater may lead to intrusion of brackish water into FGW Zone. Even in the areas not threatened by such intrusion, excessive re-circulation of groundwater may deteriorate its quality besides increasing soil salinity.

\section{Equity in Water Distribution}

Equity in the distribution of water among the users in the canal command has been an operational objective of the management of the canal systems in Pakistan. In fact, there is inequity in distribution at all levels of the systems. Within a watercourse command water delivered to the head farmers is generally 32 percent and 11 percent more than to the farmers at the tail and middle reaches, respectively. Similarly, outlet on a minor or distributary receive different amounts of water. Illegal pumping from canals and excessive losses add to the inequity in distribution [World Bank (1994a)].

\section{O\&M and Cost Recovery}

Irrigation and drainage systems have been deteriorating due to deferred maintenance and utilisation beyond design capacities. At present the recoveries are so meager that they cannot even take care of the normal operation and maintenance expenses. As a result, the allocation for the operation and maintenance have not kept pace with the increasing costs and this has resulted in the progressive deterioration of the system. The overall gap between requirement and expenditure was more than 24 percent in financial year 1992. Similarly the gap between O\&M expenditure and recoveries through water charges has been increasing, reaching 44 percent in financial year 1992. The overall gap of 44 percent increases to 57 percent if recoveries are compared with O\&M requirements instead of expenditure. The gap between O\&M and cost recoveries amounted to Rs 3062.7 million during 1991-92 [Shah and Qaiser (1994)]. 


\section{FUTURE CHALLENGES AND OPTIONS}

\section{Water Availability and Requirements}

In order to achieve the envisaged growth target in agriculture irrigation water requirements as estimated for the year 2000 and 2013 would be 143.1 and 206.4 MAF respectively as given in Table 3 [Mulk and Mohtadullah (1991)].

Table 3

Water Requirements and Availability

\begin{tabular}{lrrl}
\hline Year & 2000 & 2013 & 2025 \\
\hline Population (Million) & 148 & 207 & 267 \\
Water Requirement & & & \\
$\quad$ Irrigation & 143.1 & 206.4 & \\
$\quad$ Non-irrigation & 5.9 & 8.7 & \\
$\quad$ Total Requirements & 149.0 & 215.1 & $277.4^{*}$ \\
Water Availability** & & & \\
$\quad$ Total Surface and & & & \\
$\quad$ Groundwater & 108.7 & 107.3 & 126.6 \\
$\quad$ Shortfall & 40.3 & 107.8 & 150.8 \\
\hline
\end{tabular}

* Extrapolated.

**At Watercourse head.

Water availability for the future has been estimated at 108.7, 107.3 and 126.6 MAF (if 3 dams namely Kalabagh, Basha and Dassu are constructed) in years 2000, 2013 and 2025 respectively. Without requisite water supply, food and fibre deficits would be irrecoverable. Water Sector Investment Planning Study (1990) have reported food, fibre and edible oil shortfall of $23.5 \mathrm{~m}$. tons in year 2000 and $48.5 \mathrm{~m}$. tons in year 2013. The water availability would fall short of requirements by $40.3,107.3$ and 150.8 MAF in years 2000, 2013 and 2025 respectively which would reveal a very disastrous scenario indeed. Even in the year 2000, the deficit of 107.3 MAF would exceed the current (1995) total canal withdrawals. No substantial increase in the water supply is possible in the short run (by year 2000) because no dam can be built even if there are no political or other bottlenecks. In other words nothing can be done to reduce water shortages substantially by year 2000 nor presumably even by year 2013. Out of 35 to 40 MAF flowing to the Sea and allowing 10 MAF minimal escape below Kotri Barrage for environmental and other abstractions, a meager potential of 25 MAF is left for development of surface water resources. Groundwater residual potential of 8 MAF remains to be exploited. So overall remaining water potential both surface and sub- 
surface resources would be about 33 MAF against additional requirement of 40.3 MAF in the year 2000 and 107.3 MAF in year 2013 respectively. In nutshell there will no water to meet future requirements even if full residual potential are developed by any magic name.

\section{Need for Environmentally Sustainable Development}

The environmental problems being faced by different countries vary with their stage of development, the structure of their economies and their environmental policies. In Pakistan, the sources of pollution include saline drainage effluent, sewage, industrial waste, and agro-chemicals. Water pollution damages fisheries, and waterlogging and salinisation of the soil lowers crop yields. There are over 16.00 million hectares (ha) of irrigated land in Pakistan. Productivity on about 42.5 percent of this land area or 6.9 million ha, has declined significantly due to salinity and waterlogging. These forms of environmental degradation are associated primarily with surface irrigated agriculture in the arid and semi-arid regions which affect the physical, chemical and biological components of their ecosystem.

It is generally agreed that irrigation and drainage projects which are assisted by adequate levels of Environmental Impact Assessment (EIA) at their initial stages of planning will have greater possibilities of being more sustainable in the long term, and have higher benefit to cost ratios. This is because EIA techniques help to identify and enhance a greater range of possible positive impacts, and provide the opportunity of applying appropriate technological options and mitigatory measures into the design and operation criteria to minimise negative impacts.

Rapid population growth may make it more difficult to address many environmental problems. It is estimated that population of Pakistan, currently growing at a phenomenal rate of over three percent per annum, will increase to over 150 million by the turn of the century, thus necessitating substantial increases in food, industrial and energy output. With an annual population growth rate of 3.1 percent and the need to maintain food self-sufficiency, it will be imperative that the country conserve its existing agricultural base and the water upon which increased production will depend.

Improving the environment for development may make it necessary to raise investment rates in Pakistan by 2-3 percent of GDP by the end of this decade. This would enable stabilisation of soil conditions, increased protection of forests and natural habitats, improved air and water quality, a doubling of family planning expenditures, sharply improved school enrolment rates for girls, and universal access to clean water.

Pakistan need to have access to less pollutive technologies from the developed countries and to learn from the successes and failures of developed countries environmental policies. Policy reforms and institutional changes are required to bring about accelerated development and better environmental management. 
The primary policy objective must be to achieve sustainable agricultural production. The environment which prompts sustainable agriculture production can be determined on the basis of scientific information required for structural and institutional measures. In the process, a comprehensive EIA, if carried out properly, can not only identify major areas of environmental damage which may arise from the project, and thus provide the opportunity of adopting necessary measures in the planning, but also greatly assist in developing optimum implementation and operation schedules.

The growing recognition of the importance of environmental concerns, the rapid introduction of economic reform programmes around the world, and the trend towards democratisation and participation in the development process all point in the right direction [Afzal and Hussain (1996)].

\section{Public-Private Partnership}

\section{World Bank Approach}

In irrigation and drainage, the World Bank [World Bank (1994)] has suggested a completely new approach. The Bank wants Pakistan to commercialise or at least 'autonomies' the supply of irrigation water to farmers through market mechanism.

The bank believes it is time farmers are given "property rights" to their water and are allowed to sell/buy it and the whole thing is managed through market mechanism. It is further observed that legalised water markets based on individual water property rights, make the opportunity cost of water transparent leading to greater efficiency in use. Individual rights to water property, are considered necessary to ensure equity in distribution, thus addressing the problem of tail-enders.

The bank suggests creation of autonomous public utilities (PUs)—one for each of the 43 canal commands in the country. The PUs would in their territory sell water to farmers-individuals or preferably to farmer organisations, and charge them tariffs determined by the (provincial) government. The PUs in turn would also be free to buy water from another PU or sell to another PU. The role of farmers' organisation (FOs) is critical to the success of commercialising irrigation water. In the short term they would act as a counter balance to PUs. In the long terms, they may even come to own the PUs and operate the whole system all by themselves. World Bank envisages the new system to be put in place in four phases spread over 15 to 19 years. Phase-I comprises of enactment for PUs, FOs, water rights and water markets, Phase-II defines structure of PUs and Provincial Regulatory Commission (PRC), selection of one canal command, Phase-III would be to improve delivery efficiency and expand water supply, and Phase-IV converting rest of the canal commands to PUs and farming PWAs. 


\section{Recommended Institutional Framework ${ }^{1}$}

To make the irrigation system sustainable, O\&M gaps need to be bridged by adopting appropriate measures like cost effective O\&M, increasing water rates according to the paying capacity of small farmers. The present water charges constitute a small fraction (3-7 percent) of the net income per acre of various crops. Even then farmers are reluctant to accept any increase in water charges. Solutions suggested by World Bank address only filling the gap between O\&M and not the measures to enhance crop production for which this system is being run. Therefore, such approach which will ensure the recovery of increased water rates after enhancing crop production will be practicable under Pakistan conditions and will make irrigated agriculture sustainable.

In water sector, mostly engineering solutions were employed to solve these problems. The institutional and social aspects of the irrigation system were neglected. Any future strategy has to address these issues. The present system has to be changed to ensure sustainability of the irrigated agriculture.

We have pondered over this issue and have come to the conclusion that the above objectives can be achieved through better coordination of farmers and nation building departments (Agriculture, Irrigation and Local Government and Rural Development).

Keeping this in view, a model based on integrating these departments is suggested. The major emphasis has been laid on farmers participation through union councils. The three departments will work in close cohesion at provincial level under the Board for Irrigated Agriculture (BIA), headed by Chairman, P\&D, Secretaries for Agriculture, Irrigation, LG\&RD and farmers representative will be members of the Board. The major functions of board will include policy formulation and implementation, budgetary claims for irrigated agriculture, water rates assessment and collection procedures at provincial level. Under the Board will be different tiers at Province, Region, District and Union Council level with fair participation of farmers and these departments.

Farmers Associations organised at village level will be responsible for watercourse cleaning and maintenance, procurement of farm input under the leadership of democratic representatives (members Union Council). Farmers Associations will cooperate at village level with nation building departments in receiving farm technology, establishing demonstration farms, model farms etc.

Union Council will be considered as basic development Unit. The revenue recovery will be improved by making transparent the procedures for assessment. Crop reporting and revenue collection at various tiers. The approach will help increase farm production through integrated efforts of serving departments and farmer's organisations.

\footnotetext{
${ }^{1}$ See, Afzal and Hussain (1996a).
} 


\section{REFERENCE}

Afzal, M., and Talib Hussain (1996) Environmentally Sustainable Management of Irrigation System in Pakistan. Paper presented in International Conference on Management and Business, LUMS. Lahore. Pakistan, June 3-5.

Afzal, M., and Talib Hussain (1996a) Some Alternative Institutional Changes for Irrigation Management. Paper presented in National Conference on Management of Irrigation for Environmentally Sustainable Agriculture in Pakistan. Islamabad. 5-7 November.

Mulk, Shams ul, and Khalid Mohtadullah (1991) Water Resources Management Policies in Pakistan. Paper presented in International Workshop on Water Resource Management. Washington, D. C.: USA.

Pakistan, Government of (Various Issues) Five-Year Plans. Islamabad: Planning Commission.

Shafique, Muhammad, and A. A. Naqvi (1993) Financial and Economic Analysis of Canal Lining in Pakistan. In Proceeding Workshop on Canal Lining and Seepage. Lahore, 18-21 Oct. 393-409.

Shah, M. H., and A. H. Qaiser (1994) Policy Perspective for Making Irrigation Systems Sustainable. Islamabad: Planning and Development Division.

World Bank (1994) Pakistan Irrigation and Drainage: Issues and Options. Agriculture Operations Division, South Asia Region.

World Bank (1994a) Proceedings of the National Conference on On-farm Water Management. Islamabad: Pakistan. May 29-30.

World Bank (1995) Pakistan National Drainage Transition Programme (NDTP) Executive Project Summary.

World Bank (1995a) Pakistan, Punjab Privatisation of Groundwater Development Project. Staff Appraisal Report South Asia Region. 